\title{
Palladium Nanoparticles Supported onto Ionic Carbon Nanotubes
}

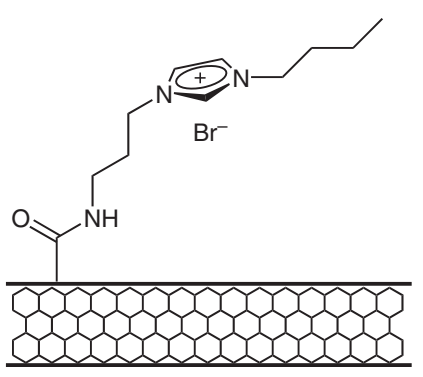

IL-f-MWCNT (1)

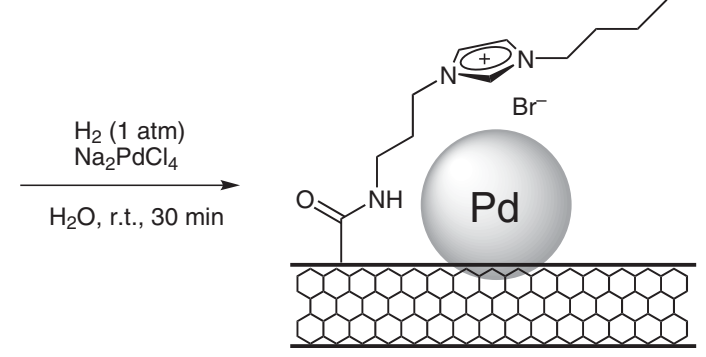

$\mathrm{Pd} / \mathrm{IL-f-MWCNT}(\mathbf{2 a})$

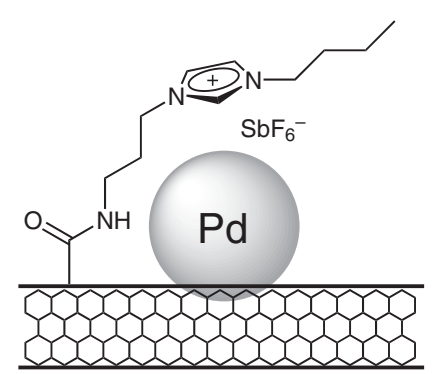

$\mathrm{Pd} / \mathrm{LL}-\mathrm{f}-\mathrm{MWCNT}$ (2c)

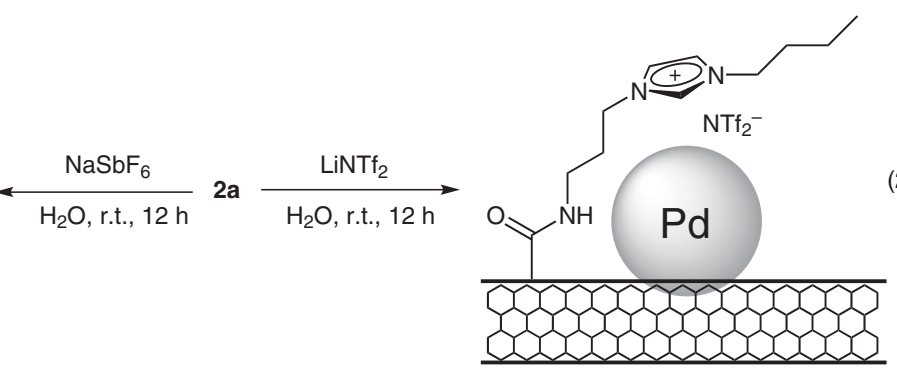

Pd/L-f-MWCNT (2b)

palladium nanoparticles

ionic carbon nanotubes

hydrogenation

Significance: An aqueous solution of IL-fMWCNTs 1 and $\mathrm{Na}_{2} \mathrm{PdCl}_{4}$ was hydrogenated under $1 \mathrm{~atm}$ of $\mathrm{H}_{2}$ pressure for 30 min at room temperature to give Pd/IL-f-MWCNTs 2a (eq. 1). Direct anion exchange of the hydrophilic $\mathrm{Br}$ anion with $\mathrm{NTf}_{2}$ and $\mathrm{SbF}_{6}$ afforded the hydrophobic $\mathrm{Pd} /$ IL-f-MWCNTs $\mathbf{2 b}$ and $\mathbf{2 c}$, respectively (eq. 2). The catalytic activities of $\mathbf{2 a - c}$ were examined for the hydrogenation of trans-stilbene in $\mathrm{MeOH}$. Pd/IL-fMWCNT 2c with the $\mathrm{SbF}_{6}$ anion showed superior catalytic activity compared to $\mathbf{2 a}$ and $\mathbf{2 b}$ (eq. 3).

\begin{tabular}{ccc}
\hline $\mathbf{2}$ & Conv. (\%) & $\mathrm{TOF} / \mathrm{mol} \mathrm{h}^{-1}$ \\
\hline $\mathbf{2 a}$ & 22 & 660 \\
$\mathbf{2 b}$ & 9 & 270 \\
$\mathbf{2 c}$ & 47 & 2820 \\
$\mathbf{2 c ^ { a }}$ & 100 & 600 \\
\hline
\end{tabular}

a $1 \mathrm{~mol} \% \mathrm{Pd}$ in $i-\mathrm{PrOH}-[\mathrm{bmim}]\left[\mathrm{SbF}_{6}\right]$ bmim $=1$-butyl-3-methylimidazolium
Comment: In this paper, the authors reported imidazolium-functionalized ionic multi-walled carbon nanotube (IL-f-MWCNT)-supported Pd nanoparticles as a catalyst for the hydrogenation of olefins. $\mathrm{Pd} / \mathrm{IL}-f$-MWCNT 2c was effectively immobilized in an ionic liquid, [bmim] $\left[\mathrm{SbF}_{6}\right]$, with extraordinary stability. Thus, 2c/[bmim] [SbF 6 ] was recovered by simple phase separation, and reused ten times without any loss of catalytic activity.

SYNFACTS Contributors: Yasuhiro Uozumi, Yutaka Matsuura Dol: 10.1055/s-2008-1072797; Reg-No.: Y04708SF 